\title{
Oxide Ion Conduction in Sintered Spinel-type Oxides $\mathrm{Zn}_{2-x / 2} \mathrm{Ti}_{1-x} \mathrm{Ta}_{x} \mathrm{O}_{4}$
}

\author{
Takao ESAKA*, Takashi IKEBE and Masahiro KAMATA
}

Received February 5, 1993 ; Accepted March 18, 1993

\section{Introduction}

The fluorite-type stabilized zirconias are the most popular oxide ion conductors. Besides these oxides, several new oxide ion conductors showing the special crystal structure have been recently reported ${ }^{1 /-3}$ ). The authors have been also exploring new ionic conductors and reported high oxide ion conduction in the scheelitetype oxides such as $\mathrm{PbWO}_{4}{ }^{4}$ ).

In another course of our synthetic research of divalent cation conductors, we surprisingly found the fairly high oxide ion (not cation) conduction in the substituted inverse spinel-type oxides based on $\mathrm{Zn}_{2} \mathrm{TiO}_{4}$. We here report the conduction behavior in the substituted phase shown by $\mathrm{Zn}_{2-\mathrm{x} / 2} \mathrm{Ti}_{1-\mathrm{x}} \mathrm{Ta}_{\mathrm{x}} \mathrm{O}_{4}$.

\section{Experimental}

The samples were prepared from the reagent grade powders of oxides $\left(\mathrm{ZnO}, \mathrm{TiO}_{2}, \mathrm{Ta}_{2} \mathrm{O}_{5}\right)$. Required quantities of reagents were mixed and fired at $900^{\circ} \mathrm{C}$. Thereafter, the samples were finely ground, pressed into pellets or disks under a pressure of 2 tons $/ \mathrm{cm}^{2}$ and sintered again at $1100-1200^{\circ} \mathrm{C}$. The crystal phase of sintered samples was identified by $\mathrm{X}$-ray diffraction.

Electrical conductivity was measured for the pellet samples by two-probe ac method (YHP4192A) using a $10 \mathrm{kHz}$ signal. Porous platinum paste was used for the electrode material. The charge carriers in the samples were investigated by oxygen gas concentration cell method using sample disc as electrolyte. The cathode gas and anode gas were 1 atm oxygen and air, respectively.

Department of Environmental Chemistry \& Technology, Faculty of Engineering, Tottori University ( Minami 4-101, Koyamacho, Tottori 680, Japan )

Key Words: Oxide ion Conductor, Solid electrolyte, Spinel-type oxide, Zinc titanium oxide, Inverse spinel structure

\section{Results and discussion}

Powder $\mathrm{X}$-ray diffraction patterns of representative samples of $\mathrm{Zn}_{1-\mathrm{x} / 2} \mathrm{Ti}_{1-\mathrm{x}} \mathrm{Ta}_{\mathbf{x}} \mathrm{O}_{4}$ are indicated in Fig. 1 . Pure $\mathrm{Zn}_{2} \mathrm{TiO}_{4}$ crystallizes in the cubic inverse spinel-

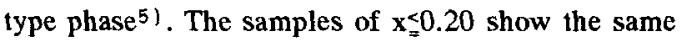
patterns as such indicating the solid solution formation.

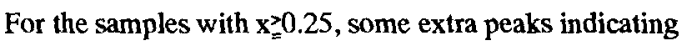
deformation of the lattice into tetragonal are observed. More than $40 \%$ tantalum-substitution brought the unknown phase mixing in the spinel phase.

Representative Arrhenius plots of conductivity measured in air are shown in Fig. 2. For pure $\mathrm{Zn}_{2} \mathrm{TiO}_{4}$, the conductivity is $2.8 \times 10^{-4} \mathrm{Scm}^{-1}$ at $1000^{\circ} \mathrm{C}$. Enhanced conductivities are observed in the samples substituted by tantalum; with increasing lanthanum content within $x_{\unrhd} \leq 0.25$ the conductivity increases little by little in the whole temperature range. At $1000^{\circ} \mathrm{C}$ the highest conductivity is observed in the $x=0.25$ sample $\left(\sigma=1.2 \times 10^{-3} \mathrm{Scm}^{-1}\right)$.

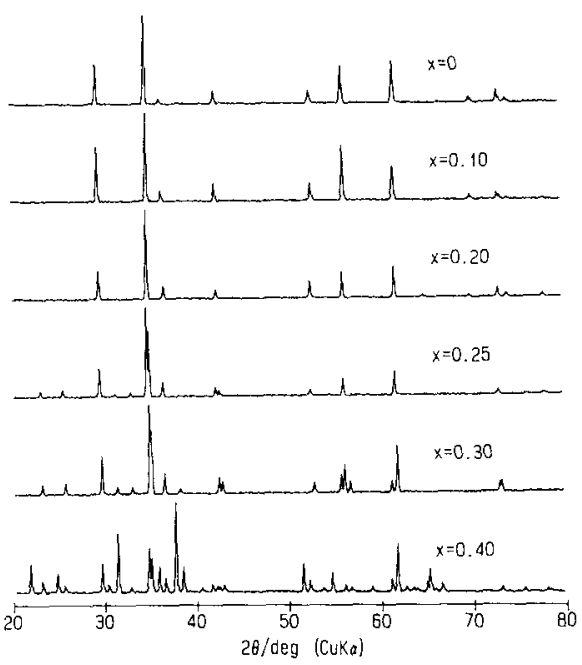

Fig.1 Representative $\mathrm{X}$-ray diffraction patterns of $\mathrm{Zn}_{2-\mathrm{x} / 2} \mathrm{Ti}_{1-\mathrm{x}} \mathrm{Ta}_{\mathrm{x}} \mathrm{O}_{4}$. 


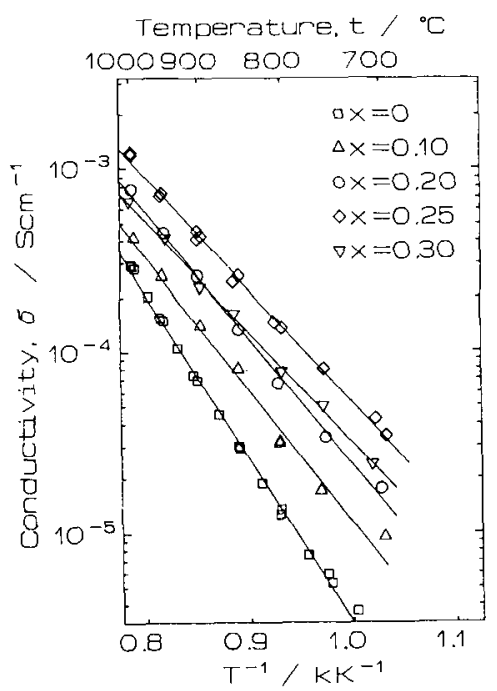

Fig. 2 Arrhenius plots of conductivity of $\mathrm{Zn}_{2-x / 2} \mathrm{Ti}_{1-\mathrm{x}} \mathrm{Ta}_{\mathrm{x}} \mathrm{O}_{4}$ measured in air.

In order to check the charge carriers in these conductors, the emf's of oxygen gas concentration cells were measured. The ratios of the measured emf's (E) to the values calculated $\left(\mathrm{E}_{\mathrm{o}}\right)$ from Nernstian equation are indicated in Fig. 3. In the case of $\mathrm{Zn}_{2} \mathrm{TiO}_{4}$, although the $\mathrm{E} / \mathrm{E}_{\mathrm{o}}$ values show a special variation with temperature and are pretty lower than unity, they are not zero in the whole temperature range, which shows that $\mathrm{Zn}_{2} \mathrm{TiO}_{4}$ itself is an electronic and ionic mixed conductor, although electronic conduction is predominant. In the samples of $x_{=}^{>0.10}$, however, those become much higher. In these cases, the electric currents could be drawn stably from the concentration cells and the shortcircuited currents were almost coincident to the calculated from the ac resistances of electrolyte and the open circuit voltages. These results mean that, although these substituted spinel-type samples $\mathrm{Zn}_{1-\mathrm{x} / 2} \mathrm{Ti}_{1-\mathrm{x}} \mathrm{Ta}_{\mathrm{x}} \mathrm{O}_{4}$ are ionic and electronic mixed conductors, their main charge carriers are oxide ions.

Furthermore, in order to examine as to the electronic charge carrier, the conductivity was measured under various oxygen atmospheres. As a result, the sample conductivity was found to increase a little with decreasing oxygen partial pressure. This denotes the ntype electronic conduction, which may be ascribed to the valence change of titanium as reported in the other titanium-containing compounds ${ }^{7}$ ).

Thus, we found that the oxide ion conduction is observed in the spinel-type oxide. Considering the crystal structure of the spinel-type oxide having so-

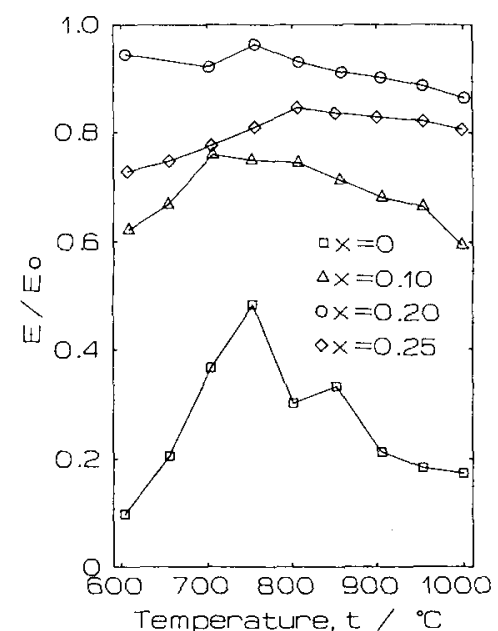

Fig.3 E/E variations of the $\mathrm{O}_{2}$-air oxygen gas concentration cells.

called closest packing of oxygen, the oxide ion migration might be not so easy. This is known from higher activation energy obtained from Fig. $1 ; 1.34 \mathrm{eV}$ for $\mathrm{x}=0.2$ sample, which has the highest ionic transport number. From the SEM observation, the grain boundary conduction was excluded, because the typical grain boundary structure like $\mathrm{Bi}_{2} \mathrm{O}_{3}-\mathrm{ZnO}$ was not formed. In the present case, therefore, the facts that $\mathrm{Zn}_{2} \mathrm{TiO}_{4}$ belongs to an inverse spinel-type oxide and has larger lattice constant $(8.47 \AA)$ than the normal spinel (8.08A) are considered to be important factors. We are now examining the other defect spinel-type oxide systems for clarification of the relations between the cation defect-type structure and oxide ion conduction, and moreover, development of new higher oxide ion conductors.

\section{Reference}

1) J.T.S. Irvine and A.R. West, Solid State Ionics, 40/41, 896 (1990).

2) F. Abraham, J.C. Boivin, G. Mairesse and G. Nowogrocki, Solid State Ionics, 40/41, 934 (1990).

3) T. Iharada, A. Hammouche, J. Fouletier, K. Kleitz,

J.C. Boivin and G. Mairesse, Solid State Ionics, 48, 257 (1991).

4) T. Esaka, T. Mina-ai and H. Iwahara, Solid State Ionics, 57, 319 (1991).

5) JCPDS card, No.25-1164.

6) JCPDS card, No.18-1487.

7) H. Iwahara, T. Esaka and T. Mangahara, J. Appl. Electrochem., 18, 173 (1988). 